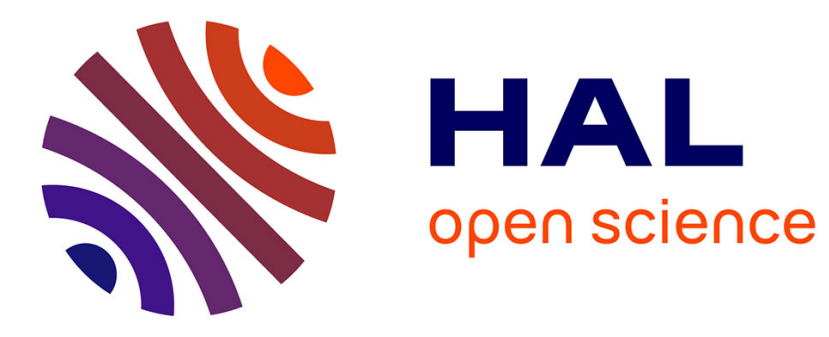

\title{
Bridges between Damage and Fracture Mechanics
}

\author{
Jacky Mazars, Gilles Pijaudier-Cabot
}

\section{To cite this version:}

Jacky Mazars, Gilles Pijaudier-Cabot. Bridges between Damage and Fracture Mechanics. Handbook of Materials behaviour models, Academic press, pp.542-548, 2005, 10.1016/B978-012443341-0/50060-

0 . hal-01007480

\section{HAL Id: hal-01007480 \\ https://hal.science/hal-01007480}

Submitted on 8 Sep 2018

HAL is a multi-disciplinary open access archive for the deposit and dissemination of scientific research documents, whether they are published or not. The documents may come from teaching and research institutions in France or abroad, or from public or private research centers.
L'archive ouverte pluridisciplinaire HAL, est destinée au dépôt et à la diffusion de documents scientifiques de niveau recherche, publiés ou non, émanant des établissements d'enseignement et de recherche français ou étrangers, des laboratoires publics ou privés. 


\section{Bridges between Damage and Fracture Mechanics}

Jacky Mazars ${ }^{1}$ and Gilles Pijaudier-Cabot ${ }^{2}$

${ }^{1}$ L3S-Institut National Polytechnique de Grenoble, 38041 Grenoble Cedex 9, France

${ }^{2}$ Laboratoire de Génie Civil de Nantes Saint-Nazaire, Ecole Centrale de Nantes, BP 92101, 44321 Nantes Cedex 03, France

\subsubsection{VALIDITY}

The purpose of this section is to provide a view on the possible connections between damage and fracture mechanics in the particular case of quasi-brittle materials (concrete, rocks, ceramics) for which linear approaches are realistic. The objective of this exercise is to offer the possibility to pass from one theory to the other during a same calculation or to obtain, from one theory, information on how to use the other. 


\subsubsection{BACKGROUND}

A unified way to present damage and fracture mechanics is through thermodynamics. It deals with energetic considerations, from which it is easy to relate local damage variables and global fracture variables. These considerations start with the assumption of a specific form of the free (reversible) energy stored in the material during straining. Let us emphasise that this section deals with the simplest possible forms of such energy. The state equations are deduced from the free energy defined as

$$
\Psi=U-T S
$$

( $U$, internal energy; $T$, temperature; $S$, entropy).

For the elementary volume at a given state of damage $D$, the free energy density is

$$
u=\frac{1}{2} \Lambda_{i j k l}^{D} \varepsilon_{i j} \varepsilon_{k l}
$$

For the overall body, damaged or partially cracked, the total free energy is written as

$$
U=\frac{1}{2} K q^{2}
$$

$\Lambda_{i j k l}^{D}$ is the local stiffness matrix at a given stage of damage, and $\varepsilon_{i j}$ is the local strain component. A load denoted as $Q$ is applied to the structure, $q$ is the corresponding displacement, and $K$ is the global stiffness. Assuming linear elasticity and isotropic damage, the relationship between $\Lambda_{i j k l}^{D}$ and the initial stiffness of the undamaged material is

$$
\Lambda_{i j k l}^{D}=\Lambda_{i j k l}(1-D)
$$

$\Lambda_{i j k l}$ is the stiffness matrix for the virgin material, with constant components depending upon the Young's modulus and the Poisson's ratio for an isotropic material which is linear elastic. At uniform and constant temperature the state laws provide the stress-strain relations and the definition of the energy release rates.

- For the damaged material, $Y$ is the damage energy release rate:

$$
\sigma_{i j}=\frac{\partial \Psi}{\partial \varepsilon_{i j}}=\Lambda_{i j k l}(1-D) \varepsilon_{k l}, \quad Y=\frac{\partial \Psi}{\partial D}=-\frac{1}{2} \Lambda_{i j k l} \varepsilon_{i j} \varepsilon_{k l}
$$

- For the cracked structure ( $A$ is the actual area of the crack), $G$ is the fracture energy release rate:

$$
Q=\frac{\partial \psi}{\partial q}=K q, \quad G=\frac{\partial \Psi}{\partial A}=\frac{1}{2} q^{2} \frac{\partial K}{\partial A}
$$


The first and second principles of thermodynamics are completely satisfied if the Clausius-Duhem inequality is also verified. For the two considered cases, we obtain

$$
-Y \dot{D} \geq 0, \quad-G \dot{A} \geq 0
$$

Since $(-Y)$ is a quadratic function and $K$ decreases when $A$ increases (see Eq. 6), these equations imply that $\dot{D} \geq 0$ and $\dot{A} \geq 0$, showing that irreversibilities correspond to micro- or macrocracking propagation.

\subsubsection{EQUIVALENCES}

Considering the similarity of the two approaches, it seems natural to go from one concept to the other [5]. One possible method is to transform a given damage zone into an equivalent crack. This equivalence is thermodynamically acceptable if the consumption of energy is the same during the two processes. Considering the case of LEFM, the critical condition of crack propagation is $-G=G_{c}\left(G_{c}\right.$ is the critical energy release rate). Then, the equivalent progression $d A$ of a crack equivalent to a state of damage in the same structure is the solution of

$$
G_{c} d A=\int_{v}-Y d D(x) d x
$$

Conversely, it is possible to derive the fracture energy $G_{c}$ from the distribution of damage around a macrocrack which propagated in the considered structure (Fig. 7.2.1). For this, one needs to know the distribution of damage around the macrocrack, which is approximated as follows. Consider an infinite body subjected to uniaxial tension in direction $1, \sigma_{11}^{0}$ with $\sigma_{11}^{0}=0$ for $i \neq 1$ and $j \neq 1$. We assume at this stage a distribution of damage denoted as $D^{0}$ and the corresponding strain field denoted as $\varepsilon_{i j}^{0}$. When small deviations from this equilibrium state are analyzed, the displacement field is the solution of the partial differential equations $\operatorname{div}\left(\dot{\sigma}_{i j}\right)=0$. The evolution law of damage is nonlocal. It is generically denoted as $D=f(\bar{\varepsilon})$ where $\bar{\varepsilon}$ is the nonlocal strain defined in Chapter 6 of this volume [6]. The equilibrium equations have a nontrivial (e.g., nonhomogeneous) harmonic solution with a wavelength which is not indeterminate. In fact, the wavelength $2 \pi / \omega$ is proportional to the internal length of the nonlocal continuum (for more details, see Reference [2]). The wavelength is also a function of the evolution law of damage. The calculation of the approximated fracture energy performed with the smallest value of the wavelength calculated for a uniaxial tensile test and corresponds to mode I crack opening. 


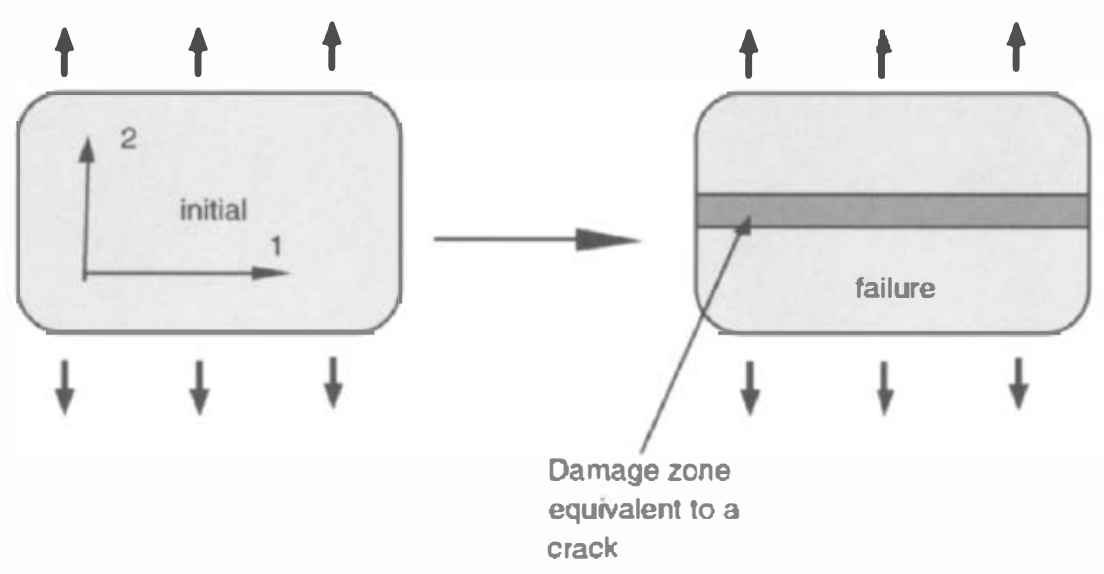

FIGURE 7.2.1 Geometry of the localization band assumed for the calculation of the fracture energy.

With the minimum wavelength, the distribution of damage perpendicularly to the crack direction is (the coordinate perpendicular to the crack path is denoted as $y$ ):

$$
D(y)=\frac{\int_{-\infty}^{+\infty} \alpha(s) \eta(y+s) d s}{\int_{-x}^{+\infty} x(s) \eta(s) d s} \text { with } \begin{gathered}
\eta(z)=\cos \left(\omega_{\max } z\right) \text { if } z \in\left[\frac{-\pi}{2 \omega_{\max }}, \frac{\pi}{2 \omega_{\max }}\right] \\
\eta(z)=0 \text { elsewhere }
\end{gathered}
$$

The energy consumption due to crack propagation is the integral of the energy dissipation at each material point in the fracture process zone, which encountered damage:

$$
G_{c}=\int_{-\infty}^{+\infty} \int_{0}^{\varepsilon_{11}(y)} \frac{1}{2} E \varepsilon_{11}^{2} \frac{\partial f}{\partial \varepsilon_{11}} d \varepsilon_{11} d y
$$

\subsubsection{HOW TO USE THESE BRIDGES}

\subsubsection{Behavior of a Structure Using a Combined Approach of Damage and Fracture Mechanics}

The structure considered is a compact tension specimen (Fig. 7.2.2a) tested by Mazars $[3,4]$. During the tests many observations and measures were made 

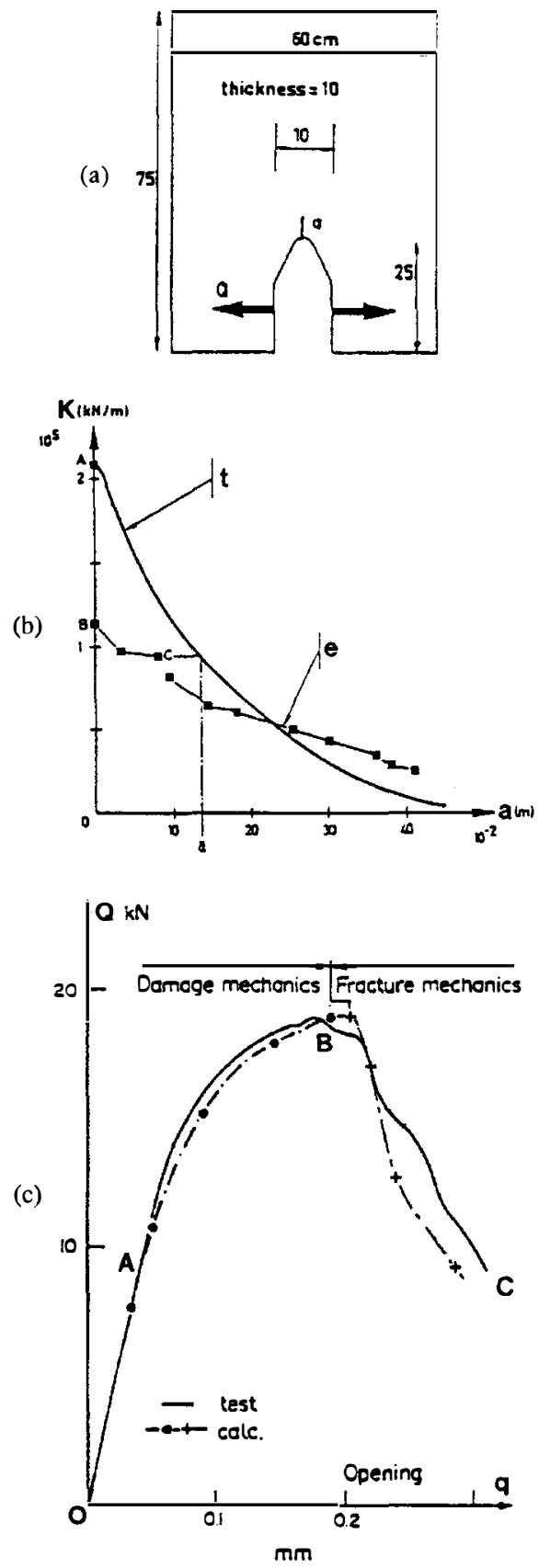

FIGURE 7.2.2 Compact tension specimen. a. Geometry. b. Evolution of the stiffness with the crack, ( $t$ ) theoretical, (e) experimental. c. Global behavior. The calculation is performed using the damage-fracture combined approach. 
showing that the global behavior includes three stages:

- OA, linear elastic;

- $A B$, damage with microcracks, but without macrocrack;

- $\mathrm{BC}$, combination of both microcracking and macrocrack.

To simulate this behavior, we propose two kinds of calculation:

- from $\mathrm{O}$ to $\mathrm{B}$ with a nonlocal damage model;

- from $B$ to $C$ with linear elastic fracture mechanic.

The bridge from the first calculation to the other directly uses the equivalent crack concept previously presented; this necessitates predetermining the evolution $K=K(A), A$ being the actual equivalent area of the crack equal to a.t ( $a$ and $t$, respectively, being length of the crack and thickness of the plate). See Figure 7.2.2b.

The following parameters have been used:

- nonlocal damage calculation: $E=34,500 \mathrm{MPa}, \kappa_{0}=1.23 \mathrm{E}-04$, $A_{t}=0.8, B_{t}=20,000, l_{c}=30 \mathrm{~mm}$ ( $\kappa_{0}$ being initial damage threshold, and $A_{t}, B_{t}$, and $l_{c}$ being non local damage parameters, see Reference [6];

- critical fracture energy at point B: $Q_{B}=18.9 \mathrm{kN}, q_{B}=0.2 \mathrm{E}-03 \mathrm{~m}$, $K_{B}=9.5 \mathrm{E}+04 \mathrm{kN} / \mathrm{m} ; \quad(-d K / d A)_{B}=51 \mathrm{E}+05 \mathrm{kN} / \mathrm{m}^{3}, \quad G_{c}=1 / 2 q_{B}^{2}$, $(-d K / d A)_{B}=102 \mathrm{~N} / \mathrm{m}$

- LEFM calculation: from Eq. 6 and as $-G=G_{c}$ at propagation, one can deduce $q=\left(2 G_{c}\right) /(-d K / d A)$, from which comes $Q=K q$.

From Figure $7.2 .2 \mathrm{~b}$ it can be pointed out:

- that the equivalent crack length at point $B$ is $a=13 \mathrm{~cm}$;

- that the experimental curve which gives the evolution of the ratio $2 / 9$ $(\# K)$ versus the crack length measured directly on the surface of the specimen is very different from the theoretical one. It confirms that the real crack appears close to the maximum load and that the evolution on the surface is faster than inside the specimen.

We may notice that the global behavior deduced from the $G_{c}$ value is close to the experimental one and the value determined from the analytical calculation $\S 7.2 .3$ is $G_{f}=115 \mathrm{~N} / \mathrm{m}$, which is close to the $102 \mathrm{~N} / \mathrm{m}$ obtained for $G_{c}$.

\subsubsection{Residual Strength of Initially Cracked Structures}

Given a crack observed in a structure, it is possible to transform the crack into an equivalent damage zone. Equation 9 provides the distribution of damage 
except at the crack tip. The radial distribution of damage at the crack tip is assumed to follow the same mathematical expression (in which the distance $r$ to the crack tip replaces the coordinate $y$. This distribution of initial damage can be projected on a finite element mesh, and the response of the initially cracked structure can be computed. Bodé et al. [2] tested such a procedure and found that it provided reasonable accuracy (10 to 30\% error on blind predictions).

\subsubsection{IDENTIFICATION OF THE INTERNAL LeNGTH}

Size effect tests directly provide the fracture energy of the material (see Reference [1]). Hence Eq. 10 yields a relationship between the evolution law of damage and the wavelength of the distribution of damage, or the internal length of the nonlocal model equivalently. Assuming that the evolution law of damage $D=f(\bar{\varepsilon})$ is completely known, the single unknown in Eq. 10 becomes the internal length. In practice, the evolution of damage is not necessarily entirely known. The model parameters in the nonlocal constitutive relations are obtained by fitting the computations of the size effect tests with the experiments. Equation 10, with the knowledge of the fracture energy $G_{c}$, is an additional piece of information which is helpful for reaching a good fit of the size effects tests more easily.

\section{REFERENCES}

1. Bazant, Z. P., and Planas, J. (1998). Fracture and Size Effect in Concrete and Other Quasi-Brittle Materials, CRC Press.

2. Bodé, L., Tailhan, J. L., Pijaudier-Cabot, G., La Borderie, C., and Clément, J. L. (1997). Failure analysis of initially cracked concrete structures. J. Engrg. Mechanics, ASCE 123: 1153-1160.

3. Mazars, J. (1984). Application de la mécanique de l'endommagement au comportement non linéaire et à la rupture du béton de structure. Thèse de Doctorat ès Sciences, Université Paris 6, France.

4. Mazars, J. (1986). A description of micro- and macroscale damage of concrete structures, Engineering Fracture Mechanics 25: 729-737.

5. Mazars, J., and Pijaudier-Cabot, G. (1996). From damage to fracture mechanics and conversely: A combined approach. Int. J. Solids Struct. 33: 3327-3342.

6. Pijaudier-Cabot, G., and Mazars, J. (2000). Damage models for concrete. Chapter 6, this volume. 